\title{
From the Anthropocene to the Anthropo-Scene
}

\author{
Leslie Sklair \\ The London School of Economics \\ and Political Science, GB (Emeritus)
}

Sklair, L.: From the Anthropocene to the Anthropo-Scene.

Philosophica Critica, vol. 5, 2019, no. 1, ISSN 1339-8970, pp. 63-68.

In the year 2000 the Nobel prize-winning atmospheric chemist Paul Crutzen and his colleague Eugene Stoermer, a lake ecologist, published a paper in an obscure geological newsletter introducing the term 'Anthropocene' (Stoermer had coined this term some years previously). In 2002 Crutzen published a one page submission in the Concepts section of Nature (probably the most influential general science journal in the world). This was entitled 'Geology of Mankind', and a prominent box under the title was labelled 'The Anthropocene'. The piece concluded: 'Unless there is a global catastrophe - a meteorite impact, a world war or a pandemic mankind will remain a major environmental force for many millennia. A daunting task lies ahead for scientists and engineers to guide society towards environmentally sustainable management during the era of the Anthropocene. This will require appropriate human behaviour at all scales, and may well involve internationally accepted, large-scale geo-engineering projects, for instance to 'optimize' climate. At this stage, however, we are still largely treading on terra incognita.' Since then the idea has been carried from its birthplace in the Earth sciences into the social sciences, the humanities, and the creative arts, a process labelled the 'Anthropo-scene'. The two books under review provide a good starting point for understanding how this unusually fertile coming together of what C.P. Snow dubbed the 'two cultures' in 1959 has come about.

Ellis, E.C. (2018): Anthropocene: A Very Short Introduction. Oxford UP 2018. Jagodzinski, J. (ed.)(2018): Interrogating the Anthropocene: Ecology, Aesthetics, Pedagogy, and the Future in Question. Palgrave 2018. 
In Anthropocene: A Very Short Introduction, Ellis illustrates the central idea of the Anthropocene as a concept in Earth science in terms of five major spheres of the Earth system: Atmosphere; Hydrosphere; Lithosphere; Biosphere; and Anthroposphere - a model first proposed by the Russian Vladimir Verdansky in 1926. The interaction of these spheres is fuelled by the sun 'forming a positive feedback system that has enhanced the dynamics of Earth's climate for more than a million years'.

Despite the warnings of previous generations of scientists, it was not until the second half of the twentieth century that alarming data from all around the planet started to emerge, providing irrefutable evidence that human impacts were beginning to have catastrophic effects in all of these five spheres and that the harmonious evolution of te Earth system itself was being compromised. Ellis credits the first conference of the UN-sponsored International Geosphere-Biosphere Programme (IGBP) in 1972 and, in particular, the IGBP report published in 2004, subtitled Planet under Pressure, as the crucial wake-up call on the rate of change in many indicators in this period (labelled the 'Great Acceleration'). This is illustrated in a frequently reproduced 24-panel chart (Figure 14 in the Ellis book). In the words of the IGBP report: 'the Earth System is now operating in a "no-analogue state",' nothing like this had ever been seen before.

While some of the science on geologic time, the Great Acceleration and specific human impacts is difficult to follow in the book, and many of the tables are hard to read (one consequence of the small format), the weight of the evidence on unwelcome change to the functioning of our home planet appears formidable. A short section entitled "The ultimate ecosystem engineers' elegantly sums up the central problem of the Anthropocene: some humans have an enormous technological capacity to alter the environments that they share with other species, usually at the expense of less powerful humans and biodiversity.

The penultimate chapter, 'Politikos', might have been better entitled 'The Anthropo-scene'. This refers to the rapid growth in social sciences, humanities and creative arts products that reference the 'Anthropocene' in their titles. Here, there have been many attempts to rename the Anthropocene - in the social sciences and humanities we find the Capitalocene (Andreas Malm) and the Chthulucene (Donna Haraway), and in the creative arts there are many more interesting suggestions (some may find all these 'cenes' a distraction from the potential dangers of the geological Anthropocene). Nevertheless, it is the term 'Anthropocene' that seems to have caught the imagination of most people who have come across the issues it raises. 
As long as it is recognised, as Ellis argues, that some humans are responsible for more Anthropogenic damage to the Earth system than others, the name is appropriate. With 45 tables and illustrations, Ellis provides us with an authoritative introduction to the Anthropocene, as we would expect from a member of the Anthropocene Working Group (which, under the energetic leadership of the geologist Jan Zalasiewicz, has achieved remarkable success in popularising the concept in scientific circles and the mass media). Ellis is also a senior fellow of the Breakthrough Institute, a leading sponsor of the idea of a 'good Anthropocene': namely, that humanity can cope with its potentially catastrophic effects, for example by means of the geo-engineering that Crutzen had recommended in his piece in Nature. Those who have read Naomi Klein's book 'This Changes Everything' might recall that she devotes a whole chapter evocatively entitled 'Dimming the Sun: the Solution to Pollution is... Pollution?' to discrediting such ideas.

Ellis has written a fascinating and erudite book. However, it has a fatal flaw, and this could be literally fatal for humankind on planet Earth. While Ellis does discuss the question of species extinction, like most Earth scientists and journalists he focuses on the impacts of humans in the destruction of animal and plant species and generally fudges the question of human survival in the worst-case Anthropocene scenario. He references a 2015 paper by Gerardo Ceballos et al on these issues, but not a later study that concludes: 'All signs point to ever more powerful assaults on biodiversity in the next two decades, painting a dismal picture of the future of life, including human life'. I may not be alone in thinking that this book is one on-going contradiction. Ellis documents the damaging effects of the Anthropocene on almost every page but manages to remain optimistic, always endorsing the 'good Anthropocene' within the socio-economic status quo. Like most scientists, he considers Earth Summits to have failed and mitigating efforts of governments and corporations to be feeble. Yet, the concept of 'existential risk' to human life is passed over in one short sentence. This leaves us with the burning question: when human survival is at stake is the risk of hoping for the best and avoiding any radical change that disturbs the status quo worth taking?

If Ellis provides us with a very short introduction to the Anthropocene, J. Jagodzinski offers a very long introduction to the Anthropo-scene in Interrogating the Anthropocene. While he does engage with the natural science of the Anthropocene in a socio-political context, none of the central scientific figures in Ellis's book (Verdansky, Paul J. Crutzen, William Ruddiman, Zalasiewicz) make it into [[stet]] index, where we do find Gilles 
Deleuze and Félix Guatarri, Bruno Latour, Isabelle Stengers and Haraway. The editor's introduction is a tour de force with 58 pages and over 200 references - a survey of formidable scholarship. The following fifteen chapters range far and wide, forging neglected but often very enlightening connections between, for example, the Anthropocene and 'Planet Factory' (Nick Dyer-Witheford); Pokémon GO (Jason J. Wallin); Sounding (Mickey Vallee); and Empathetic Movement (Leslie Sharpe). There are also chapters which throw new light (both theoretical and substantive) on much-discussed Anthropocene topics, notably Matthew Tiessen on capital; Janae Sholtz on geophilosophy; David Fancy on Geoartistry; Bradley Necyk et al, and Patti Pente on art; and Michael Truscello on catastrophism.

The book is part of a series entitled 'Educational Futures', bringing to our attention the obvious but inconvenient truth that if we are to understand and cope with the Anthropocene, it must find a place in general education. The final section, 'Pedagogical Responses', crystallises the unique contribution of this collection. Ted Stolze's chapter 'Against Climate Stoicism: Learning to Fight in the Anthropocene' interrogates Roy Scranton's much-discussed book Learning to Die in the Anthropocene - 'existentially riveting but unremittingly bleak' in its assertion that we have to learn to die not as individuals, but as a civilisation. Stolze frames his critique within the Stoic distinction between the few things we (humans) control and the many things we cannot. Stolze, a philosopher, argues that climate change denialism has been replaced by climate change stoicism, and that the key question for philosophy in the Anthropocene is not learning to die (even with dignity) but learning to fight, and an important part of the fight is deconstructing monolithic views of human nature. In support of his optimistic view that another (more benign) Anthropocene is possible, he cites St. Paul, Martin Luther King, the image of the militant philosopher and Jeremy Brecher's climate insurgency manual. However, his hope that salvation may lie in a carbon-neutral eco-socialist state future will, sadly, not convince many readers.

Nathan Snaza's 'The Earth is not "Ours" to Save' engages with another three influential Anthropo-scene authors, the historian Dipesh Chakrabaty, the social scientist (small 's') Latour, and the philosopher Timothy Morton - all recruited to flesh out his idea of 'bewildering education'. His starting point is what he calls 'everyday life in a highly petroliumized world' [sic], where humans don't seem able to imagine not being the most important geological agent, a belief structured into educational institutions and practices. Chakrabarty's argument that the Anthropocene brings with it a particular conception of being human has been widely 
discussed, and Snaza's suggestion that it connects to the education system (which includes a careful critique of Critical Social Theory) seems to me to be very significant.

Moving on to the work of Latour, Snaza takes the proposition that human and nonhuman actants should be 'treated the same' as a further pointer as to what needs to change if we are to start to comprehend the implications of the Anthropocene for the increasingly discredited nature/ culture divide. However, he is less impressed with Latour's conception of a single collective with a Constitution (an obscure idea that Snaza interprets as somewhat fascist) nd its implications for education. Morton is best known for his innovative concepts of hyperobjects (like the vast temporality and spatiality of the Anthropocene) and the mesh (the interconnectedness of all things or entanglements). These ideas lead to the following conclusions for bewildering education. First, agency is not limited to humans; indeed, education, Snaza argues, should be reconceived as a process that leads all involved away from being human, away from the restricted teleology, dualism and sexism of Man's dominion over nature. Second, we need to let go of our desire to plan, replacing it by creating a space of radical uncertainty about the future. Third, dealing with the Anthropocene should not involve some sort of Collective (presumably he means the capitalist state, which appears to be the route the UN and the so-called 'environmental movement' have taken so unsuccessfully up to now). He concludes by arguing that learning to fail as geological agents would be a good educational outcome.

The final chapter, Jessie Beier's 'Dispatch from the Future: Science Fictioning (in) the Anthropocene', skilfully constructs a 'science fiction' fable full of ridiculous ideas, all of which the endnotes confirm as 'real' (AAMP, SRM, trustX, KBT). Beier provides some interesting data on the Alberta education system and goes on to argue that 'one of the most troubling things about the Anthropocene is the sheer number of people it fails to trouble'. This statement will be hard to accept if you are trapped in the academic bubble, but recent research on how the Anthropocene is represented in mass media around the world confirms that most media coverage conveys what can be termed reassurance (i.e. good Anthropocene) narratives, relatively few alarms being raised. Quoting from Sun Ra, the Afrofuturist musician and poet, that the possible has been tried and failed. Now it's time to try the impossible', Beier mobilises this sentiment in support of a positive stand between pessimism and optimism in the Anthropocene, which encourages the thought that many of the chapters in the book would have benefited from an attempt to create a Gramscian 
concept of hegemony for the digital, Anthropocene age, how the 'common sense' of capitalism and the state becomes 'nonsense' when confronted with the dangers of the Anthropocene. Nevertheless, this book is an invaluable, and in some respects uniquely original, resource for all those scholars in the social sciences, humanities and creative arts who are grappling with the Anthropocene. An added bonus to this collection are the nineteen intriguing watercolours by Mia Feuer, who explains in a brief chapter how an artist interrogates petrochemicals through her art, from the Suez Canal to the Tar Sands of Alberta. The sooner affordable paperback and e-book editions of this collection are available, the better.

\section{Leslie Sklair}

Emeritus Professor of Sociology

London School of Economics

LONDON WC2A 2AE

United Kingdom

l.sklair@lse.ac.uk 